\title{
Aplicação de ferramentas computacionais para o desenvolvimento do ensino de crianças com autismo: um Mapeamento Sistemático da Literatura
}

\author{
Title: Application of Computational Tools for the development of teaching of children with \\ autism: a Systematic Mapping of Literature
}

Martony Demes da Silva

Universidade Federal do Piaui -UFPI

mardemes@gmail.com

\author{
André Castelo Branco Soares \\ Universidade Federal do Piaui -UFPI \\ andre.soares@ufpi.edu.br
}

\author{
Igo Coutinho Moura \\ Instituto Federal do \\ Maranhão - IFMA/Timon \\ igo.moura@ifma.edu.br
}

\begin{abstract}
Resumo
Crianças caracterizadas com o Transtorno do Espectro Autista (TEA) demandam atenção especial para com os cuidados em seu cotidiano, inclusive durante o processo de ensino e aprendizagem escolar. Ensinar crianças autistas requer o uso de métodos e ferramentas diferenciadas devido às dificuldades cognitivas, sociais e comunicativas desses indivíduos. Diante disso, neste trabalho, avaliaram-se diversas pesquisas publicadas que tratam sobre intervenções terapêuticas (aplicadas às crianças autistas) que são apoiadas por recursos computacionais. Esse tipo de abordagem se mostra eficaz no incremento do desenvolvimento de várias habilidades, possibilitando o avanço no aprendizado da criança e potencializando o trabalho do educador em sua prática de ensino. Este trabalho apresenta um Mapeamento Sistemático da Literatura com o propósito de investigar e interpretar as tendências e as lacunas dos avanços no uso de tecnologias computacionais para o ensino de crianças com TEA. Os resultados desta pesquisa geraram embasamento teórico para tomada de decisão em relação a questões de pesquisas futuras. Os resultados obtidos indicam que as ferramentas tecnológicas incrementam significativamente o desenvolvimento do ensino de crianças com autismo. Identificou-se também que as tecnologias móveis são adotadas como o principal instrumento tecnológico no processo de ensino e aprendizagem.
\end{abstract}

Palavras-Chave: Autismo, tecnologias, ensino, mapeamento sistemático.

\section{Abstract}

Children characterized with Autism Spectrum Disorder (ASD) demand special attention to care in their daily lives, including during the school teaching and learning process. Teaching autistic children requires the use of differentiated methods and tools due to the cognitive, social and communicative difficulties of these individuals. Therefore, in this study, we evaluated several published studies that deal with therapeutic interventions applied to autistic children, which are supported by computational resources. This type of approach is effective in increasing the development of various skills, allowing for the advancement of the child's learning and enhancing the educator's work in his teaching practice. This work presents a systematic mapping of the literature with the purpose of investigating and interpreting the trends and gaps in the advances in the use of computational technologies for teaching children with ASD. The results of this research and work generated theoretical basis for decision making in relation to future research questions. The results indicate that the technological tools significantly increase the development of the teaching of children with autism. It is also highlighted that it has been identified that mobile technologies are adopted as the main technological instrument in the teaching and learning process.

Keywords: Autism, technologies, teaching, systematic mapping

\section{Introdução}

Cite as: Silva, M. D., Soares, A. C. B. \& Moura, I. C. (2019). Application of Computational Tools for the development of teaching of children with autism: a Systematic Mapping of Literature (Aplicação de Ferramentas Computacionais para o desenvolvimento do ensino de crianças com autismo: um Mapeamento Sistemático da Literatura). Brazilian Journal of Computers in Education (Revista Brasileira de Informática na Educação - RBIE), 27(3), 351-368. DOI: 10.5753/RBIE.2019.27.03.351 
O Transtorno do Espectro Autista (TEA) é um transtorno global do desenvolvimento caracterizado por gerar prejuízos nos indivíduos quanto às suas habilidades de interação social e comunicação, além de haver a presença de comportamentos repetitivos e estereotipados (APA, 2013). De acordo com o Manual de Diagnóstico e Estatística dos Transtornos Mentais V (DSMV), o TEA é um transtorno do neurodesenvolvimento que acomete diferentes áreas do desenvolvimento (APA, 2013). Geralmente, manifesta-se nos indivíduos ainda na infância. Nessa fase, a criança típica refina seu sistema neuromotor e desenvolve suas habilidades de comunicação, generalização, abstração e socialização. Já crianças que estão no espectro enfrentam dificuldades no processo de refinamento e desenvolvimento de habilidades inerentes ao desenvolvimento típico.

Crianças com TEA enfrentam diversas dificuldades de aprendizado e alfabetização, devido à existência de comportamentos atípicos que se manifestam de forma heterogênea e em diferentes níveis. Diante disso, é essencial que elas realizem - muitas das vezes, concomitantemente - tratamento psicológico, fonoaudiológico e ocupacional, além de necessitarem de uma forma de ensino e alfabetização diferenciada. Por conta disso, há uma natural demanda de tempo e de abordagens personalizadas que considerem o atual nível da criança e as suas demandas mais urgentes (Mattos e Nuernberg, 2011). Diante disso, a literatura mostra que indivíduos com TEA apresentam características inerentes que influenciam na aprendizagem dessa população. Tais peculiaridades tornam o aprendizado por meio de métodos tradicionais mais desafiador, sendo necessários métodos de ensino diferenciados para novos comportamentos (Ozand, 2016; CDC, 2014).

Segundo o Center of Diseases Control and Prevention (CDC), órgão dos Estados Unidos equivalente ao Ministério da Saúde no Brasil, uma em cada 68 crianças é diagnosticada com TEA naquele país (CDC, 2014). No Brasil, estima-se que existam mais de dois milhões de indivíduos com TEA. Tais dados evidenciam que há um número significativo de indivíduos que possuem características de TEA. Por conta disso, tal assunto demanda atenção e necessita de esforços da comunidade científica visando ao avanço no tratamento e no acompanhamento de tais sujeitos.

Recomenda-se, em crianças com TEA, a realização de tratamento terapêutico com equipe multidisciplinar (Psicologia, Fonoaudiologia, Psicopedagogia, Terapia Ocupacional, dentre outras áreas). O tratamento de uma criança com TEA demanda esforço intenso, dedicação e acompanhamento do processo no consultório e no domicílio. É comum que os resultados de evolução com o tratamento sejam obtidos pela criança a médio e longo prazos, o que pode gerar incertezas e frustrações na família. Em se tratando do ensino escolar, em especial na fase de alfabetização, os desafios se tornam ainda maiores.

Crianças com TEA demonstram interesse em manusear e utilizar recursos computacionais (celular, tablet, jogos eletrônicos etc.). Por conta disso, essas ferramentas são inseridas cada vez mais nas terapias e nos processos de ensino e aprendizagem desses sujeitos (Passerino et al., 2006).

Nesse sentido, o objetivo desta pesquisa é identificar e investigar as tendências e as lacunas dos avanços no uso de tecnologias computacionais para o ensino de crianças com TEA, por meio de um Mapeamento Sistemático da Literatura, o qual contempla estudos primários sobre ferramentas computacionais que contribuem para o desenvolvimento do ensino de crianças autistas. Para alcançar tal intuito, utilizou-se de Questões de Pesquisa, de modo a respondê-las por meio da análise e da síntese dos artigos disponíveis sobre o tema. Infere-se, a partir de pesquisas em bases de dados utilizadas neste trabalho, que não foram encontradas na literatura revisões formais com o mesmo objetivo.

No escopo deste artigo, consideram-se ferramentas computacionais os dispositivos móveis (tablets e smartphones), os computadores de mesa (desktop) e os dispositivos tecnológicos 
vestíveis, como relógios, óculos etc. Essa delimitação se tornou necessária devido à grande quantidade preliminar de artigos encontrados nas bases de dados.

Este trabalho também considera as abordagens ABA, PECS e TEACCH para responder a alguns dos questionamentos propostos no estudo. A primeira, ABA, vem da sigla em inglês, do termo Applied Behavior Analysis, que significa Análise do Comportamento Aplicado. É uma abordagem da Psicologia utilizada para a compreensão do comportamento. Já PECS (Picture Exchange Communication System) é um tipo de prancha visual de comunicação e é utilizado para auxiliar na comunicação de crianças autistas não verbais. E TEACCH é uma estrutura de treinamento para apoiar a execução de objetivos educacionais e terapêuticos de forma organizada e sistematizada. Possui horário e atividades bem individualizados, com apoio visual na execução das tarefas.

O restante deste artigo está organizado da forma descrita a seguir. Na Seção 2, são apresentados conceitos sobre a pesquisa bibliográfica, o mapeamento sistemático e a metodologia aplicada nesta pesquisa. A Seção 3 mostra a aplicação da metodologia de análise, por meio do mapeamento sistemático no trabalho. A Seção 4 apresenta os resultados obtidos no mapeamento. Por fim, a Seção 5 apresenta a discussão e a conclusão.

\section{Pesquisa bibliográfica sistemática}

Comumente, o passo inicial no processo de investigação científica é a realização de uma pesquisa bibliográfica (PB). Ela é responsável pela imersão em referenciais teóricos, trabalhos relacionados e até no "estado da arte" em um tema específico, com vistas ao reconhecimento da fronteira do conhecimento. Métodos de pesquisa bibliográfica de maneira sistemática tiveram seu início na Medicina, sendo propagados em outras áreas de estudo, como nas Ciências Sociais, na Economia e na Computação - especificamente na Engenharia de Software.

As pesquisas bibliográficas não produzem um conhecimento novo. Porém, esse tipo de pesquisa é fundamental para a realização de estudos científicos. É a base ou a fonte de informações que servirá como ponto inicial de análise para possíveis novas contribuições. Sendo assim, contribui para o aumento do domínio do conhecimento do pesquisador sobre determinada linha de pesquisa.

A PB pode ser definida como o estudo de artigos, teses, livros e outros tipos de trabalhos disponibilizados por editoras e indexadas (Wazlawick, 2010). Pode ser considerada como um levantamento de toda a bibliografia já publicada em revistas, livros, publicações diversas e na imprensa escrita (Lakatos e Marconi, 1991). Petersen (2008) ressalta que houve, como consequência do crescimento e da evolução de determinada linha de pesquisa, um crescimento do número de pesquisas e resultados obtidos. Nesse sentido, é importante sumarizar e sintetizar determinado conhecimento, pois se pode apresentar uma visão geral da área em pesquisa. Além disso, outro ponto relevante é avaliar o estado da arte de uma determinada área do conhecimento com o propósito de apresentar lacunas a serem exploradas.

Dentro desse universo, as pesquisas bibliográficas podem ser de quatro tipos: a PB tradicional, as revisões sistemáticas de literatura, as análises bibliométricas e os mapeamentos sistemáticos de literatura.

a) Tradicionais: são pesquisas que não possuem um processo sistemático definido. A experiência do pesquisador é que orienta a pesquisa. Nesse sentido, não existe garantia de resultados imparciais: eles podem ou não inclinar para dados que concordam com as hipóteses apoiadas pelo autor.

b) Revisões: revisões sistemáticas de literatura (RSL) objetivam identificar e avaliar de forma confiável e imparcial todos os trabalhos relevantes sobre determinado assunto, entregando 
de forma sintetizada os principais resultados encontrados (Detroz et al., 2015). Assim, a revisão tem o propósito de identificar e entregar todas as pesquisas relevantes à linha de pesquisa, e não somente aquelas que corroborem para a hipótese apoiada pelo pesquisador. Outras denominações são survey, review, levantamento ou panorama.

c) Bibliometria: diz respeito a PBs que aplicam métodos estatísticos e matemáticos para a obtenção de informações quantitativas sobre livros e outros meios de comunicação. Nesse tipo, a relevância de um artigo ou a influência de certo pesquisador a partir do número de citações feitas a esse artigo contribui para a coleta dos dados objetivados.

d) Mapeamento Sistemático da Literatura: oferece uma visão geral da área de estudo, quantificando os resultados. Assim, é possível identificar tendências e lacunas de pesquisas a serem estudadas. Esse tipo pode ser identificado por outros nomes, como mapeamento sistemático de estudos, overview ou meta-análise. Outros detalhes serão citados nas subseções a seguir.

Para este trabalho foi utilizado o Mapeamento Sistemático da Literatura porque oferece uma visão quantitativa dos trabalhos relacionados. Além disso, deve-se levar em consideração o significativo número de trabalhos selecionados. Nesse cenário, tornou-se viável realizar uma análise comparativa sistemática - que é o MSL - a partir de um conjunto de estudos primários cientificamente selecionados.

\subsection{Mapeamento Sistemático da Literatura}

O Mapeamento Sistemático da Literatura (MSL) é um método científico capaz de identificar, interpretar e sumarizar os trabalhos relevantes para determinada linha de pesquisa, área ou fenômeno de interesse de forma não tendenciosa e replicável (Kitchenham, 2007). Essa metodologia de pesquisa tem como objetivo específico sintetizar as evidências em relação a uma determinada questão de pesquisa (QP) por meio dos estudos primários obtidos. Há diversos motivos para a realização de um MSL. Dentre eles, destacam-se: 1) a necessidade de sumarizar toda evidência empírica sobre determinado tratamento ou tecnologia; 2) a possibilidade de identificar lacunas na área; 3) a indicação de pontos de futura investigação (Kitchenham, 2007). Na subseção a seguir, serão apresentados os passos principais abordados para a execução do MSL e utilizados nesta pesquisa.

\subsection{Metodologia aplicada}

O procedimento utilizado neste artigo para a execução do Mapeamento Sistemático da Literatura se baseia nas diretrizes de trabalhos de (Kitchenham et al. 2004). (Kitchenham et al. 2004) tratam, de forma sistemática, dos trabalhos desenvolvidos em uma determinada área do conhecimento e, em seguida, apresentam um resumo visual dos resultados encontrados. Para alcançar esses resultados, inicialmente, utiliza-se um protocolo predefinido. A condução deste artigo se subdivide em três etapas: planejamento, execução e sumarização/resultados (Kitchenham, 2007).

Na primeira etapa, o planejamento, os pesquisadores devem realizar a execução do estudo. Nesse processo, são definidos os objetivos, as questões de pesquisa, as bases de dados que serão utilizadas, a string de busca a ser aplicada nas bases de dados, os critérios para inclusão e exclusão dos trabalhos obtidos, os formulários para extração de informações relevantes, dentre outros aspectos. A Figura 1 apresenta os componentes necessários para o planejamento citados anteriormente. 


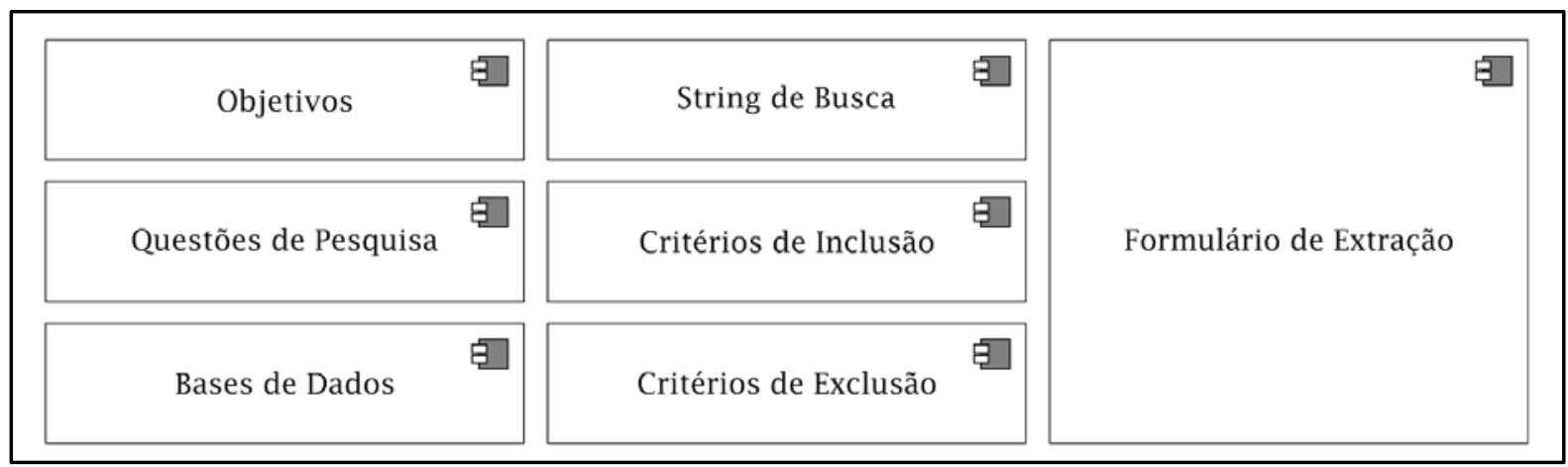

Figura 1: Primeira etapa do MSL - Planejamento (Braga, 2016)

A segunda etapa é a execução, representada na Figura 2. Primeiramente, o pesquisador deve aplicar a string de busca nas bases de dados para obter o conjunto de estudos primários. Em segundo lugar, é necessário aplicar os critérios de inclusão/exclusão, considerando-se, inicialmente, a leitura do título e do resumo dos trabalhos obtidos na busca. Em seguida, é realizada a leitura completa dos trabalhos incluídos para extração de dados relevantes. Além disso, durante a execução, pode ser realizada uma análise das referências presentes nos trabalhos selecionados, a fim de que se busquem trabalhos correlatos que não foram encontrados nas bases de dados.

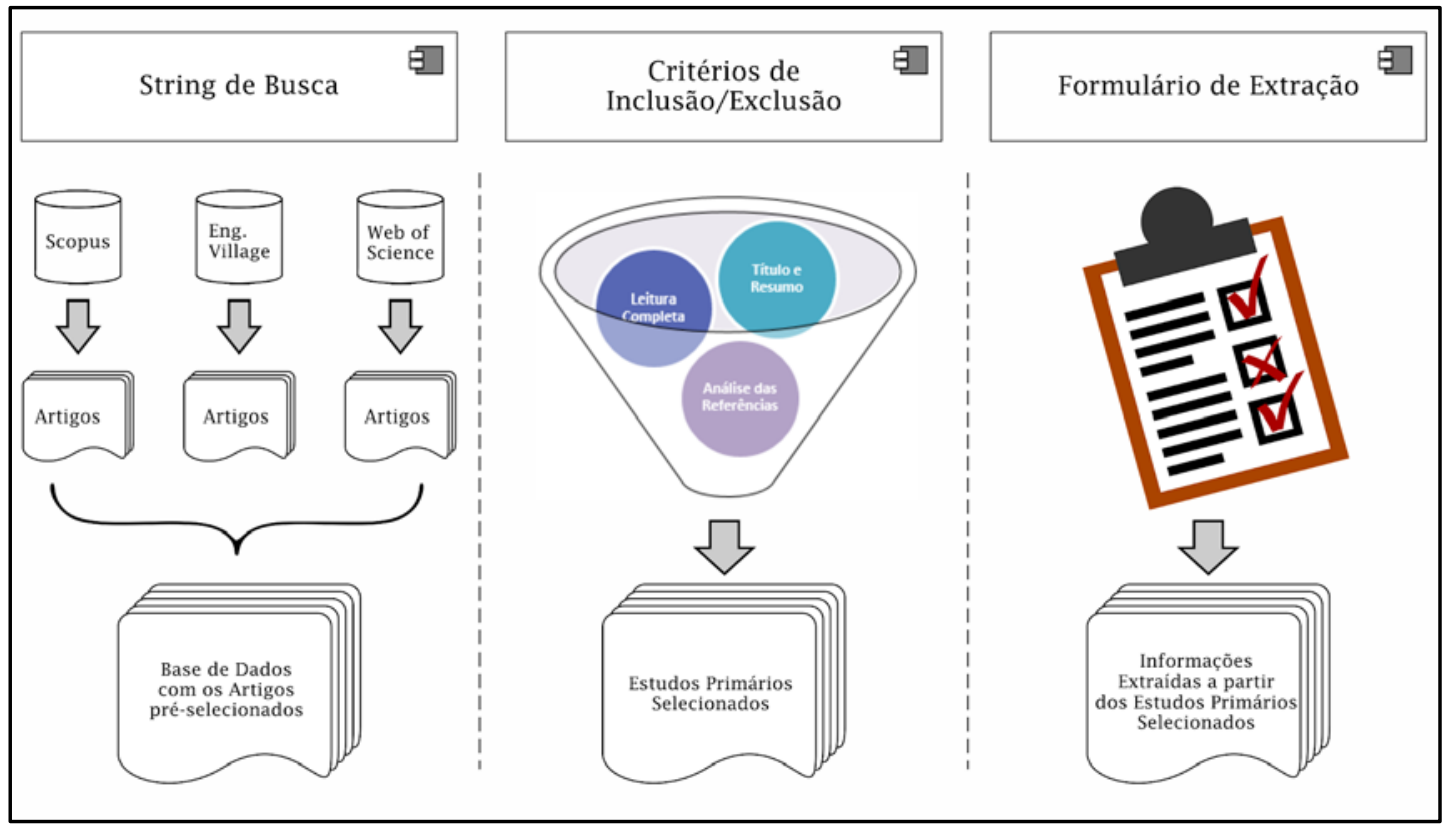

Figura 2: Segunda etapa do MSL - Execução (Braga, 2016)

Por fim, a terceira etapa é destinada à sumarização dos resultados. Nela, são organizadas as informações em gráficos e tabelas, a fim de facilitar o entendimento do tema pesquisado. Nessa fase, também ocorre a discussão sobre os resultados obtidos, apresentando-se as principais contribuições do mapeamento sistemático. A seguir, será descrito o que foi utilizado em cada uma das partes do MSL.

\section{Metodologia de análise}

A metodologia utilizada neste artigo é o processo de Mapeamento Sistemático, descrito na seção 2.2 . 


\subsection{Planejamento}

Inicialmente, os objetivos (citados na Seção anterior) foram modelados. Em seguida, as questões de pesquisa e as strings de buscas foram construídas. Logo depois, quatro bases de dados relevantes foram selecionadas, nas quais se aplicaram as strings de busca. Ainda nessa mesma fase, foram projetados os critérios de inclusão (CI) e os critérios de exclusão (CE) dos trabalhos obtidos. Por fim, os formulários de extração foram preparados e alinhados com os objetivos da pesquisa.

Vale destacar que o planejamento deve ser realizado de maneira bem orquestrada com o propósito da investigação - se possível, sempre realizando testes preliminares, a fim de simular ou avaliar se os resultados iniciais são condizentes com o proposto. Caso contrário, se torna mais complexo realizar mudança no plano depois da obtenção dos resultados, tendo em vista o quantitativo de trabalhos avaliados.

Ressalta-se que a metodologia objetiva sintetizar as evidências em relação a uma determinada questão de principal (QP) por meio dos estudos primários citados. Para alcançar os objetivos da pesquisa, faz-se uso de questões secundárias (QSs), que dão suporte ao que se pretende alcançar na questão principal. A seguir, são descritas as questões de pesquisa relacionadas.

i) Questões de pesquisa: Para alcançar os objetivos citados, elencaram-se questionamentos, sendo uma questão principal e seis questões secundárias. São elas:

a) QP: Como as ferramentas tecnológicas potencializam o desenvolvimento do ensino de crianças autistas?

b) QS1: Quais estratégias/abordagens da análise do comportamento para o ensino são utilizadas?

c) QS2: Quais plataformas computacionais são utilizadas?

d) QS3: O sistema utilizado acessa os dados local ou remotamente?

e) QS4: Existem estratégias com uso de inteligência artificial?

f) QS5: A proposta computacional é adaptável às necessidades da criança com TEA?

g) QS6: As abordagens com uso de tecnologias são comparadas com o método tradicional?

ii) Strings de busca: Para responder às questões levantadas, inicialmente, foram construídas strings com palavras-chaves do tema da pesquisa. É proposto um número exaustivo de strings e seus sinônimos, com o objetivo de chegar ao máximo de artigos relacionados ao assunto indagado. Dessa maneira, ficarão selecionados artigos relevantes da linha de pesquisa do mapeamento. A Figura 3 demonstra a composição de strings de busca para o Scopus. O processo de busca foi realizado com a aplicação da string de pesquisa em diferentes bibliotecas, havendo adaptação ao mecanismo de busca de cada uma delas. As strings estão disponíveis em: $<$ https://goo.gl/MwexjG>.

\section{Scopus}

TITLE-ABS-KEY ( ( gadget OR android OR ipad OR tablet OR device portable OR device mobile OR earphone OR app OR "computer application" OR software OR framework OR "computational technology" OR "smart device" OR tool OR "computing technology" OR "Soft Computing" OR "Computing service" OR programs OR "software engineering" OR application OR "ubiquitous computing" OR games OR robots OR "agents touch" OR handheld OR "handheld" OR "assistive technology" OR "augmented reality" OR interface OR 3d ) AND ( 
autism OR "autism spectrum disorder" OR asd OR autistic OR adhd OR "Attention Deficit" OR

"Hyperactivity Disorder" OR "behavior problems" OR "functioning autism" OR "asperger syndrome" OR "Childhood Disintegrative Disorder" OR "Pervasive Developmental Disorder" ) AND ( educational OR alphabetized OR "to literate" OR educate OR literate OR learn OR learning OR teach OR training OR instruct OR discipline OR assisting OR school OR intervention speech OR empowerment ) ) AND PUBYEAR $>2010$

Figura 3: Strings de busca aplicadas na base de dados Scopus

iii) Base de dados: As strings foram submetidas às máquinas de buscas em quatro bases de pesquisas: Scopus, Web of Science, PubMed e APA. A escolha por essas plataformas é justificada pelo objetivo de coletar o máximo possível de trabalhos com abrangência internacional. Ressalta-se, também, que essas bases de buscas são indexadoras de outras bases de dados, e, com isso, a abrangência é bem considerável. O período considerado na pesquisa foi de 2011 a 2016.

iv) Critérios de inclusão (CI) e exclusão (CE): Esses critérios são aplicados para selecionar os artigos a partir do resultado da coleta das bases de dados citadas. Considerando-se apenas os artigos primários, os trabalhos selecionados são apenas aqueles que estão de acordo com o critério de inclusão (Kitchenham, 2007). Vale destacar, por definição, que trabalhos disponíveis representam os trabalhos que podem ser obtidos por meio do acesso permitido dentro da universidade onde foi realizada a consulta. Optou-se por limitar apenas os idiomas inglês, espanhol ou português, com o objetivo de abranger apenas trabalhos incluídos nessas línguas, em que já se obtém uma abrangência relevante. Os critérios estão listados na Tabela 1, a seguir:

Tabela 1: Critérios de inclusão e de exclusão

\begin{tabular}{|l|l|}
\hline & Descrição do critério \\
\hline CI-1 & $\begin{array}{l}\text { O trabalho aborda tecnologias computacionais que apoiem o ensino de criança no espectro } \\
\text { autista e (AND) }\end{array}$ \\
\hline CI-2 & $\begin{array}{l}\text { O trabalho foi publicado e está disponível integralmente em bases de dados científicas para } \\
\text { visualização e/ou download. Idiomas considerados: inglês, espanhol e português e (AND) }\end{array}$ \\
\hline CE-1 & $\begin{array}{l}\text { O trabalho não aborda tecnologias que apoiem o ensino a criança no espectro autista ou } \\
\text { (OR) }\end{array}$ \\
\hline CE-2 & $\begin{array}{l}\text { O trabalho NÃO está disponível em formato digital ou impresso (estudos incompletos } \\
\text { também serão desconsiderados) ou (OR) }\end{array}$ \\
\hline CE-3 & O trabalho não está em inglês, espanhol ou português. \\
\hline
\end{tabular}

v) Formulário de extração: Esse item é criado com base nas questões da pesquisa. É aplicado na etapa de execução, após a seleção, e objetiva encontrar os resultados quantitativos para as questões da pesquisa. O formulário foi criado na ferramenta baseado nas questões de pesquisa secundárias (QSs). Essas questões estão disponíveis com os resultados sumarizados neste link: <https://goo.gl/Nm2rHP>. Ressalta-se que, no mesmo formulário, há questões que foram utilizadas para dar suporte a respostas de questões desta pesquisa e que não foram dispostas de maneira direta neste trabalho.

\subsection{Execução}

Nesta segunda etapa, foi posto em prática o que foi planejado na etapa anterior. Aplicaram-se as strings de busca nas quatro bases de dados. O resultado da busca foi um conjunto composto por 3.855 artigos pré-selecionados no formato bibtex. Logo em seguida, os arquivos nesse formato são inseridos em uma ferramenta de suporte a MSL, chamada The End (Braga, 2016), a qual 
possibilitou a realização de todas as etapas de maneira sistematizada, on-line e colaborativa entre os autores do trabalho. A Figura 4, a seguir, destaca a página inicial do mapeamento selecionado.

Detalhes do Mapeamento

Titulo: Uso de tecnologias computacionais para ensino de crianças autistas: um Mapeamento Sistemático

Descrição: Identificar e analisar estudos primários e ferramentas computacionais para ensino e aprendizagem de crianças autistas.

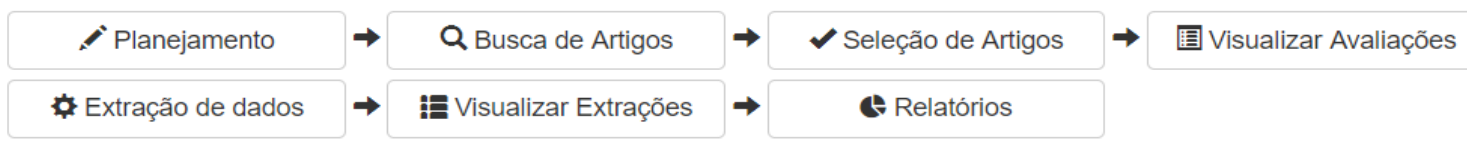

Andamento da Seleção de Artigos:

Andamento da Extração de Dados:

Figura 4: Tela da ferramenta de um MSL para realização de todas as suas etapas

Por meio da Figura 4, acima, destaca-se que a ferramenta utilizada - The End - possibilita a realização de todas as etapas do MSL: desde o planejamento, seguindo para a execução, com os botões "Busca de Artigos", "Seleção de Artigos", "Visualizar Avaliações”, "Extração de dados" e "Visualizar Extrações", até a etapa final de sumarização, fechando com a opção de visualizar "Relatórios”. O link da ferramenta está disponível em: <https://goo.gl/yn7CBK>.

Em seguida, dois pesquisadores (A e B) realizaram a seleção utilizando os critérios de inclusão e de exclusão. Levou-se em consideração, inicialmente, a leitura do título e do resumo dos trabalhos obtidos na busca. Assim, após a leitura dos 3.855 artigos pré-selecionados, levando em consideração os critérios de inclusão e de exclusão e a retirada de artigos duplicados, chegouse ao resultado dessa seleção, que foram 218 artigos primários. Ressalta-se que essa quantidade, inferior ao número inicial de artigos coletados nas bases de dados, é coerente, pois também ocorreu a remoção de artigos duplicados e não condizentes com o tema (conforme protocolo). Além disso, consideraram-se apenas as tecnologias computacionais especificadas na Seção 1.

Vale ressaltar, com base em Kitchenham (2007), que, após a seleção de cada participante, A e B, existe um passo intermediário, que é o confronto dessas seleções. Essa atividade é relevante porque possibilita a redução dos vieses nas seleções, sendo que artigos que divergiram serão reavaliados. Os participantes se reúnem, discutem e entram em consenso sobre essa seleção. Assim, cada um entra com sua justificativa, devendo haver um acordo para definir se um artigo deve ser aceito ou não. Além disso, um terceiro autor (C) pode fazer uma reavaliação, caso os dois autores (A e B) não cheguem a um acordo.

Com o objetivo de qualificar este trabalho, realizou-se uma análise de concordância entre os resultados obtidos pelos participantes. Para essa análise, os pesquisadores A e B realizaram um teste Kappa (Dixon e Massey, 1957). Esse teste possibilita determinar o grau de concordância e assegurar a confiabilidade dos critérios de inclusão e de exclusão. Ou seja, quanto maior o nível de concordância, maior a confiabilidade dos resultados. As divergências foram solucionadas por meio de discussão entre os pesquisadores. Dessa forma, dos 230 trabalhos que foram préselecionados, em 12 houve discordância quanto à seleção. Esses 12 estudos foram reavaliados por um terceiro pesquisador (C), junto aos demais autores, em reunião, que decidiram em consenso pela exclusão dos artigos. Totalizaram-se, assim, 218 aceitos. 
Após a seleção, os artigos aceitos representam os trabalhos que responderão às questões de pesquisa definidas no protocolo do mapeamento. Esses estudos foram lidos por completo pelos pesquisadores, e, em seguida, os formulários de extração foram preenchidos. Diante desse contexto, obtiveram-se as informações relevantes para a sumarização dos dados (próxima etapa).

\subsection{Sumarização}

Nesta última etapa, é possível cruzar duas questões do formulário e gerar gráficos de bolhas dessas questões, ilustrando informações relevantes sobre a linha de pesquisa. Assim, com o objetivo de ilustrar potenciais pontos de futura investigação, apresenta-se um mapa da área com gráficos de bolhas bidimensionais, no qual o diâmetro da bolha é determinado pela quantidade de publicações correspondentes às coordenadas (X, Y). Dessa maneira, visualizam-se as tendências e as lacunas por meio desses gráficos gerados. Além disso, é possível gerar outros gráficos auxiliares com dados sumarizados e organizados após os processos de seleção e de extração.

O objetivo das informações dispostas nestes gráficos e nessas tabelas geradas é demonstrar quantitativamente um mapa das informações e visualizar as respostas para as questões da pesquisa. Para efeito estrutural, os resultados deste trabalho foram organizados na próxima Seção. A lista com os artigos aceitos e com detalhes dos dados sumarizados está disponível neste link: $<$ https://goo.gl/Nm2rHP $>$.

\section{Resultados}

Os resultados obtidos no MSL são apresentados e discutidos objetivando responder às questões de pesquisa da metodologia aplicada e, assim, alcançar o objetivo esperado nesta pesquisa. A Figura 5 apresenta a distribuição dos trabalhos pelas bases de dados escolhidas entre os anos de 2011 a 2016.

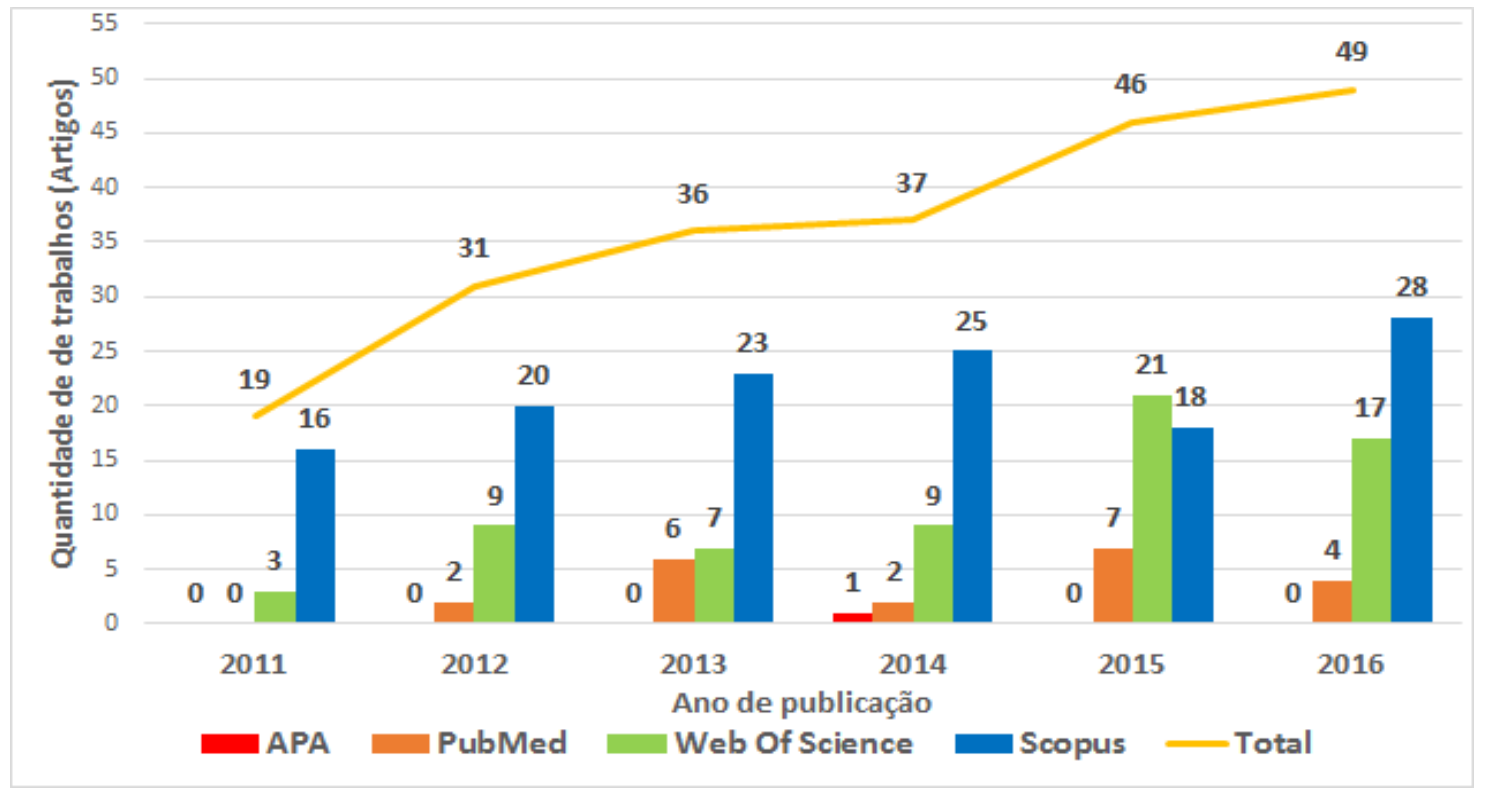

Figura 5: Distribuição de artigos por base de dados e ano de publicação

A linha contínua da Figura 5 apresenta o total de artigos publicados por ano. Observa-se que esse aumento significativo sugere, para esta linha de pesquisa, que esse é um tema de interesse da comunidade científica, devido ao crescimento relevante, passando de 19 trabalhos em 2011 para 49 trabalhos no ano de 2016. Assim, reforça-se o potencial do uso de tecnologias para o ensino de crianças com autismo nas pesquisas durante esse período. Vale destacar que, em 
paralelo, várias tecnologias evoluíram durante esse mesmo período, e isso também contribuiu para crescimento de pesquisas nessa área.

Outra observação pertinente se refere aos dados relacionados às bases de dados. O Scopus, por ser um repositório de artigos e trabalhos científicos de grande relevância, aparece com maior quantitativo de trabalhos. Por outro lado, a APA e a PubMed, mais direcionadas para a área de saúde, possuem poucas publicações sobre o uso de tecnologias para o ensino de crianças com TEA. Isso era algo previsível, mas pode evidenciar para os profissionais dessa área a necessidade de trabalhar mais nessa linha de pesquisa. A seguir, são dispostas as respostas para as questões. Vale destacar que, durante a pesquisa, é possível visualizar dados de determinada categoria divergentes em diferentes gráficos. Isso acontece porque há determinada categoria ou abordagem que ocorrem em mais de outro tipo, e isso pode sugerir que os resultados não são compatíveis ou divergem.

QS1: Quais estratégias/abordagens da análise do comportamento para o ensino são utilizadas?

Ao analisar o uso de abordagens (ou estratégias) que dão suporte ao ensino de crianças com TEA, por meio da Figura 6, nota-se que há 185 artigos que não citam (neste caso, não utilizam) uma estratégia de ensino. Vale ressaltar, segundo a literatura, a importância do uso de uma estratégia de ensino diferenciada. Uma criança com TEA possui características peculiares, se comparada com uma criança neurotípica. Nesse cenário, presume-se uma lacuna para trabalhos futuros. A soma dos valores dispostos no gráfico da Figura 6 não condiz com o total de artigos selecionados, porque há trabalhos que utilizam duas abordagens ao mesmo tempo.

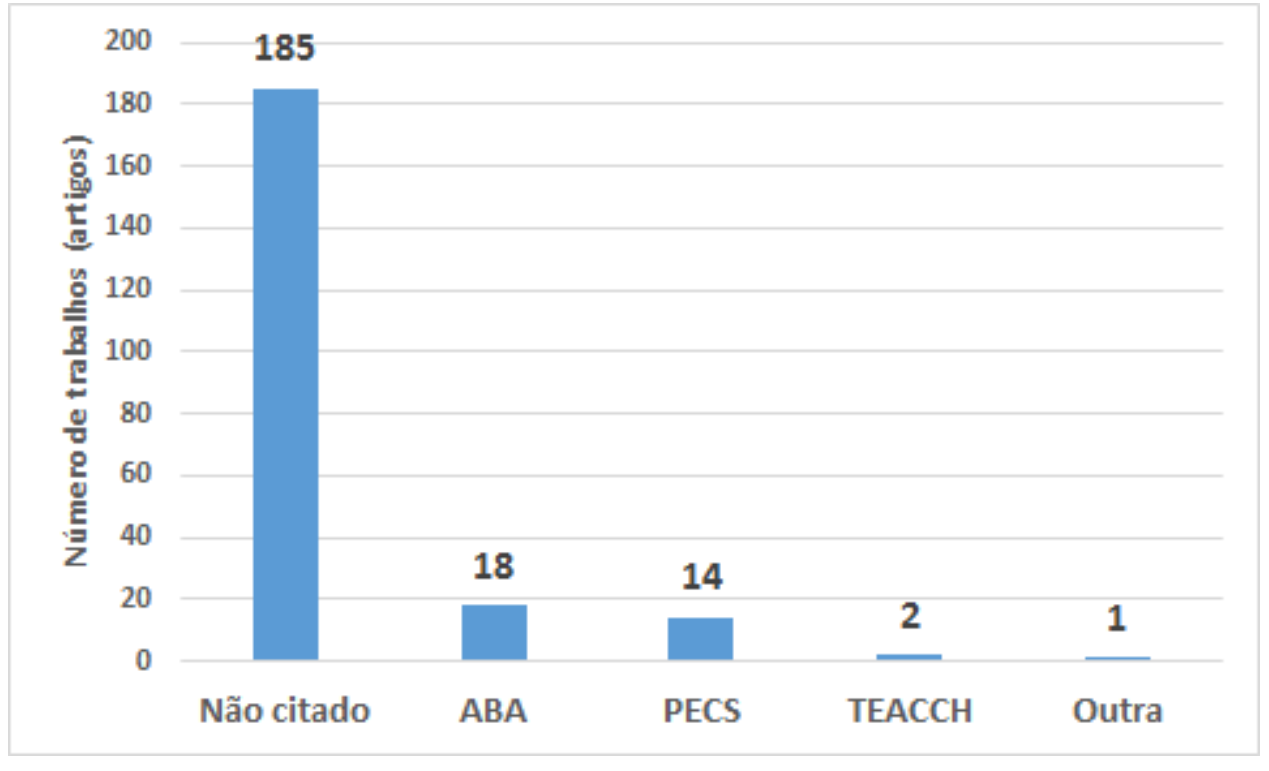

Figura 6: Número de abordagens/estratégias tratadas nos artigos

QS2: Quais plataformas computacionais são utilizadas?

A quantidade maior de plataformas utilizadas é de tecnologias móveis (60\%), conforme mostra a Figura 7. Com isso, infere-se que o uso dessas ferramentas se dá com maior preferência em intervenções no ensino de crianças com TEA. 


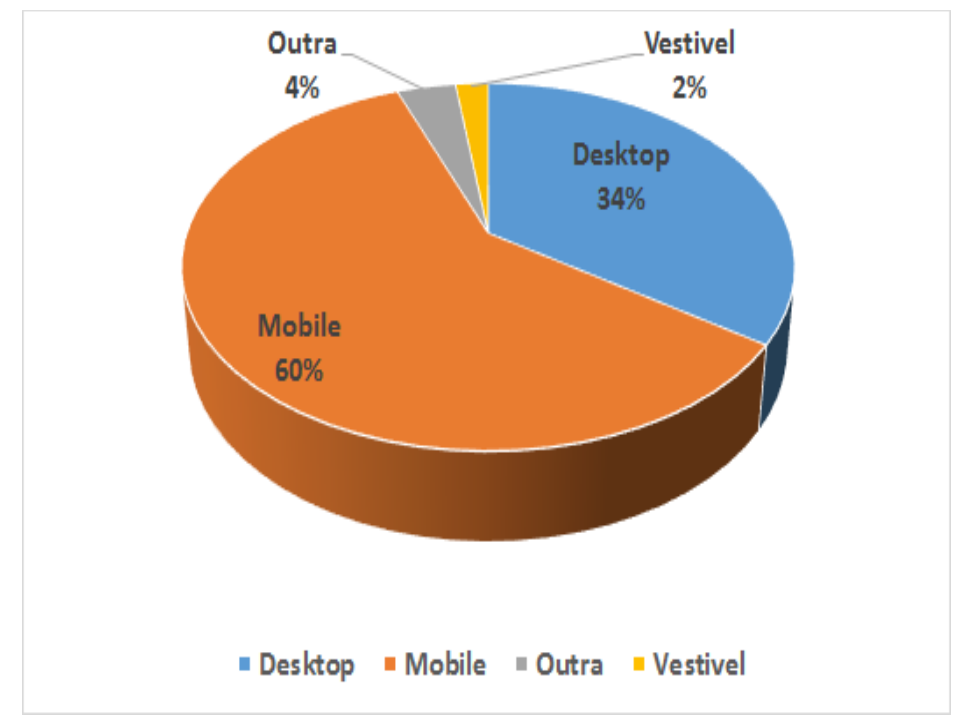

Figura 7: Quantitativo por plataformas computacionais

Nesta pesquisa, consideram-se ferramentas do modelo desktop como sendo tanto os sistemas feitos para rodar apenas em computadores (PCs, notebooks e outros) como as aplicações web e também as plataformas mobiles (iPhone, tablets, smartphones, dentre outros).

Outra análise pertinente está dentro da gama de novas ferramentas propostas. Conforme é visualizado na Figura 8, a seguir, para dispositivos móveis, são 90 artigos (o que equivale a 62\% dos trabalhos propostos de novas ferramentas) e, para desktop, são 52 trabalhos (o equivalente a $61 \%$ dos artigos com proposta de ferramentas). Isso sugere que a maioria (ambos os aspectos com índice acima de 60\%) dos trabalhos objetiva propor novas ferramentas computacionais. Isso tanto para as plataformas mobile quanto para desktop.

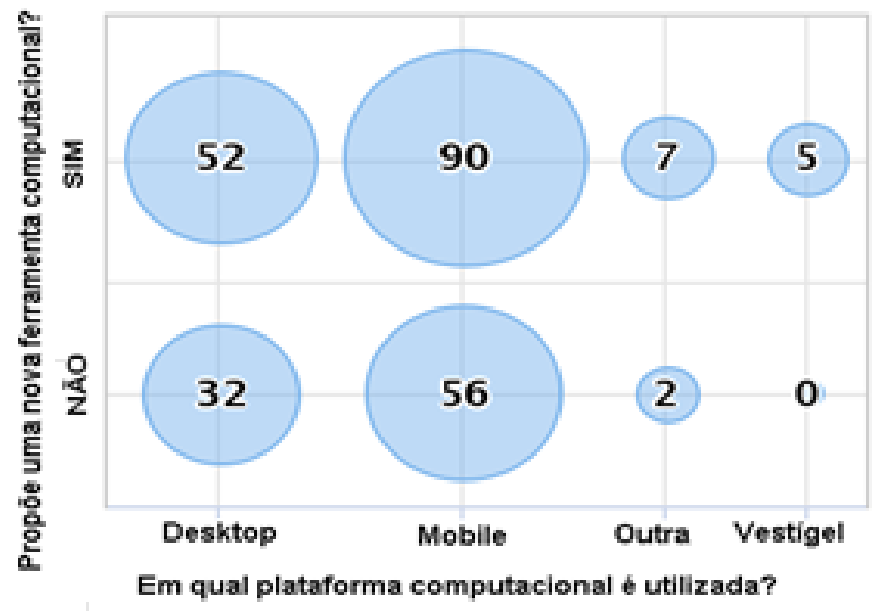

Figura 8: Quantitativo das plataformas computacionais utilizadas

QS3: O sistema utilizado acessa os dados local ou remotamente?

O propósito desse questionamento é descobrir qual abordagem é mais utilizada para acessar os dados das ferramentas: localmente ou remotamente. Contextualiza-se, para este trabalho, que a forma local significa acessar uma base de dados apenas localmente, na respectiva ferramenta, ou especificamente dentro do dispositivo. Já o modo remoto, por definição, significa que a aplicação ou ferramenta acessa sua base de dados em um local remotamente, como, por exemplo, a nuvem de dados. Partindo desses princípios, por meio da Figura 9, verifica-se que há uma quantidade, considerável, de 110 trabalhos que acessam os dados apenas no próprio dispositivo, de forma 
local. Já especificamente dentro do universo das tecnologias móveis, o total é de 146 artigos. E 72 estudos desse tipo de dispositivo ainda trabalham de forma local, sem acessar uma base de dados remota.

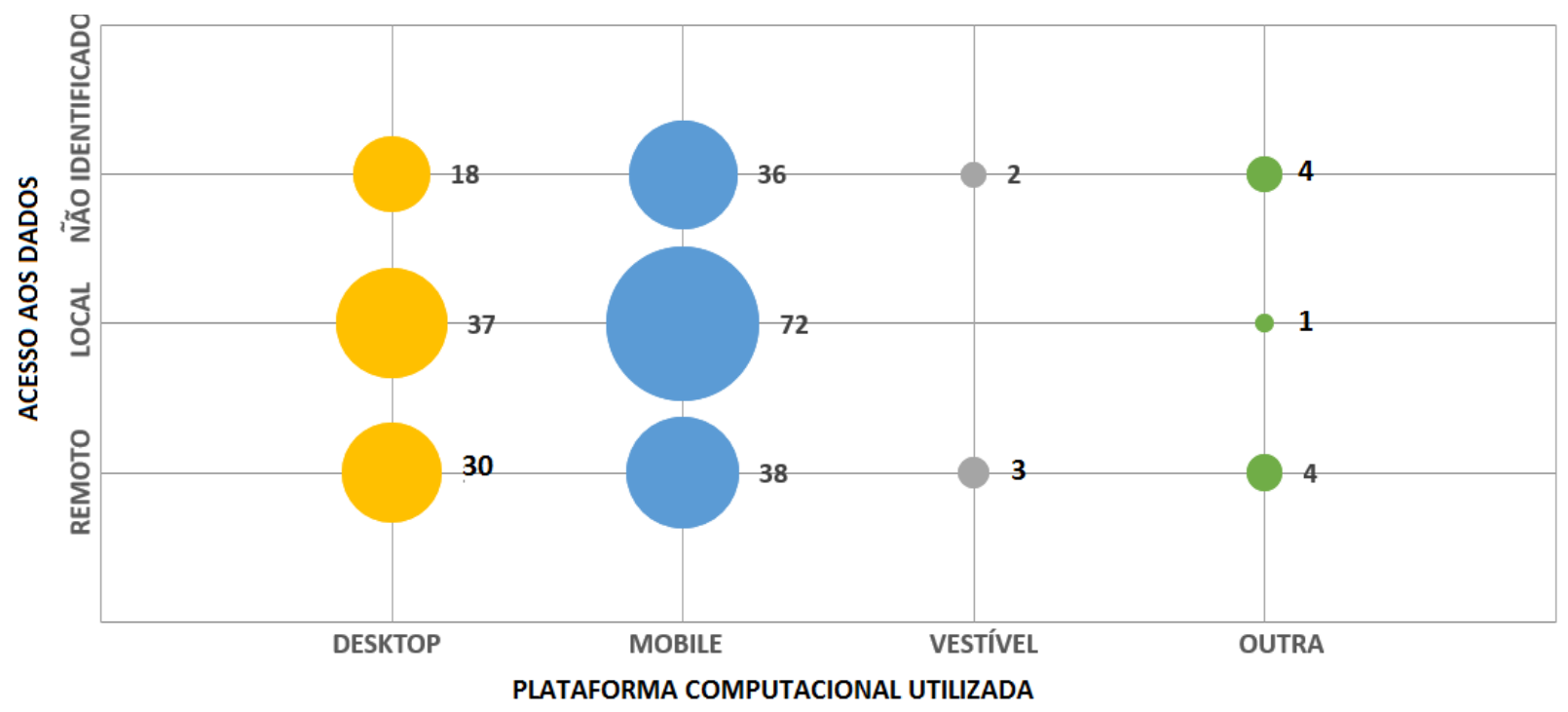

Figura 9: Comparativo entre abordagem de acesso local/remoto com plataforma tecnológica

QS4: Existem estratégias com o uso de inteligência artificial (IA)?

A utilização de IA ainda é pouco abordada nos trabalhos sobre tecnologias computacionais para o ensino de crianças autistas. Apenas 12 trabalhos (Figura 10) consideram o uso desse recurso. Vislumbram-se, assim, oportunidades em pesquisa abordando o uso de tecnologias computacionais para o ensino a crianças com TEA com o uso de IA.

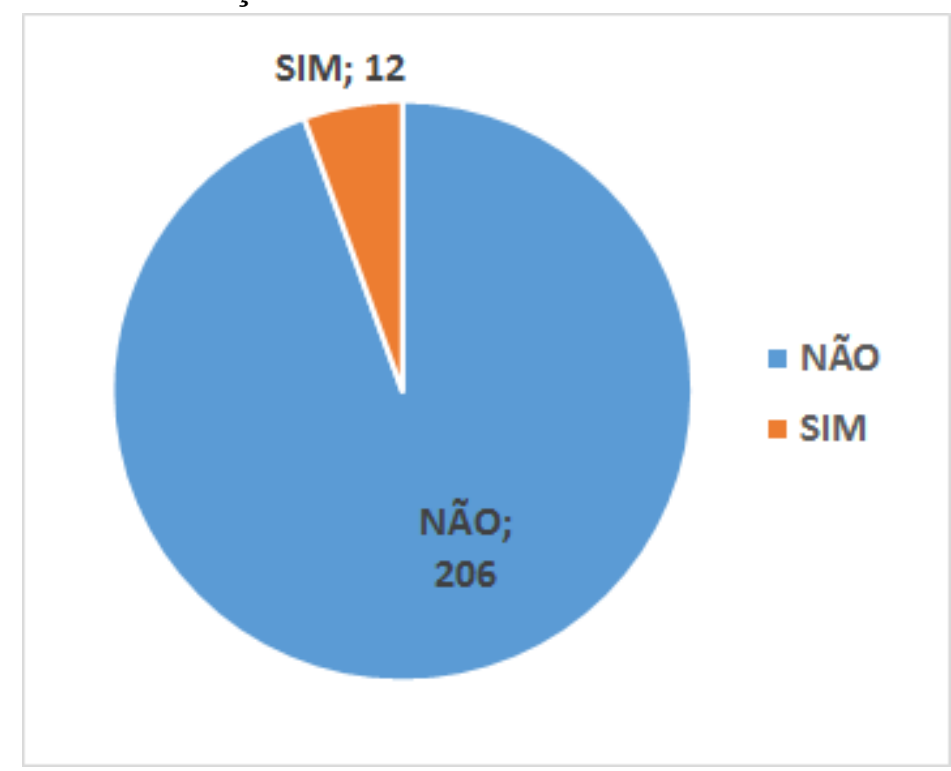

Figura 10: A estratégia utilizada faz uso de Inteligência Artificial?

Por outro lado, os trabalhos que propõem nova ferramenta computacional apresentam um quantitativo significativo utilizando IA (com 11 trabalhos), levando em consideração os trabalhos que não propuseram uma nova ferramenta computacional (apenas um artigo com abordagem com IA), como é visualizado na Figura 11. 


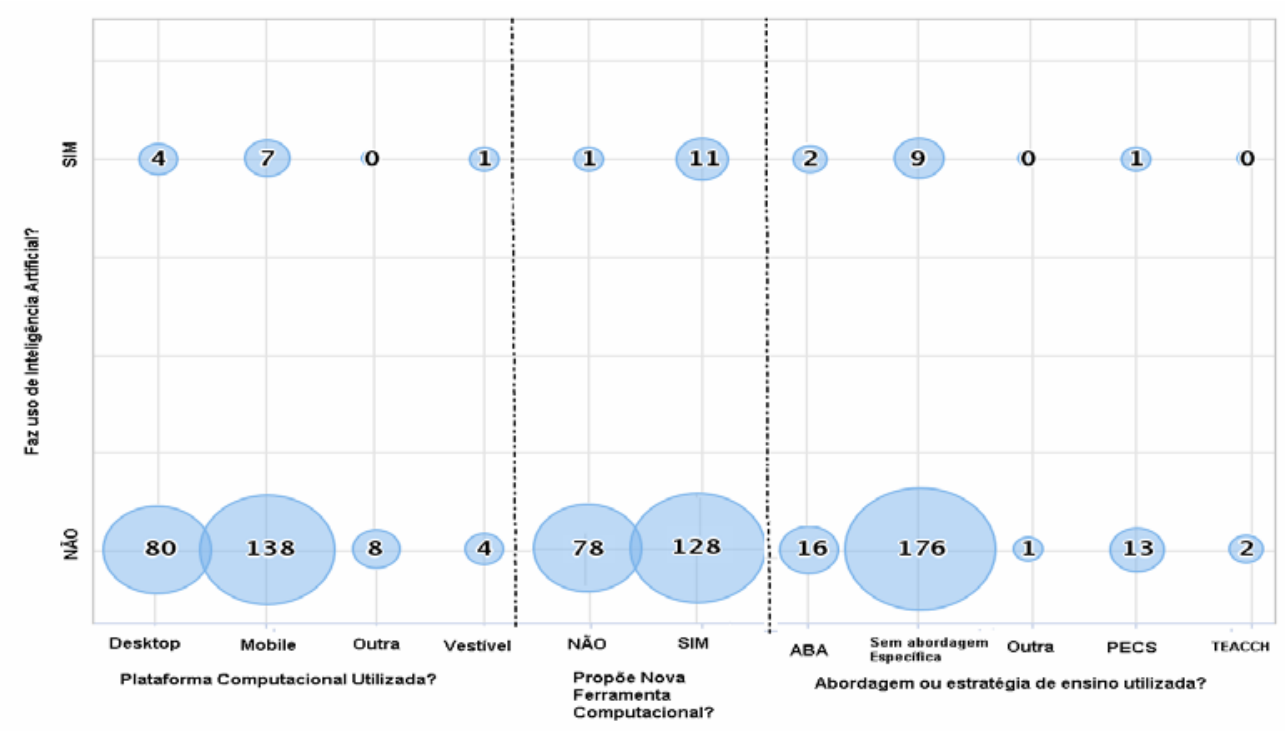

Figura 11: Comparativo com o uso de Inteligência Artificial: plataforma computacional, nova ferramenta e abordagem de ensino

QS5: A proposta computacional é adaptável às necessidades da criança?

Por meio do gráfico gerado, disposto na Figura 12, tem-se uma perspectiva do quantitativo de trabalhos que apresentam ferramentas que permitem adaptação de atividades conforme o nível de desenvolvimento da criança. A maioria dos trabalhos, com 189 artigos, não possibilita personalizar as atividades com base no repertório da criança com TEA.

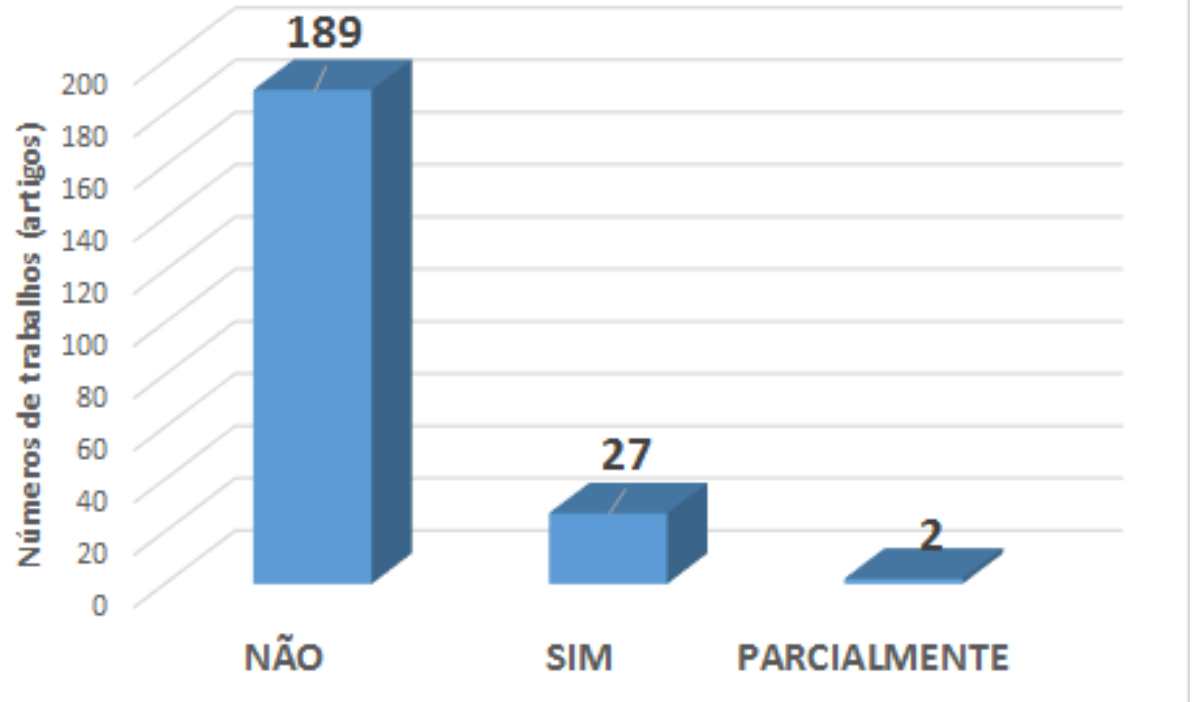

Figura 12: Número de artigos que apresentam ferramenta computacional adaptável às necessidades ou ao desenvolvimento da criança

Ressalta-se que uma ferramenta computacional customizável ou adaptável às necessidades da criança deve possibilitar a personalização das atividades conforme o repertório vigente de cada sujeito. Dessa maneira, permite-se a construção de atividades compatíveis com o desenvolvimento de cada indivíduo, evitando-se atividades desnecessárias, incompatíveis com seu currículo ou que são avançadas para seu estado atual.

A Figura 13 ilustra gráfico comparativo entre trabalhos que abordam a adaptação ao nível do indivíduo com TEA e trabalhos com proposta de ferramenta computacional. 


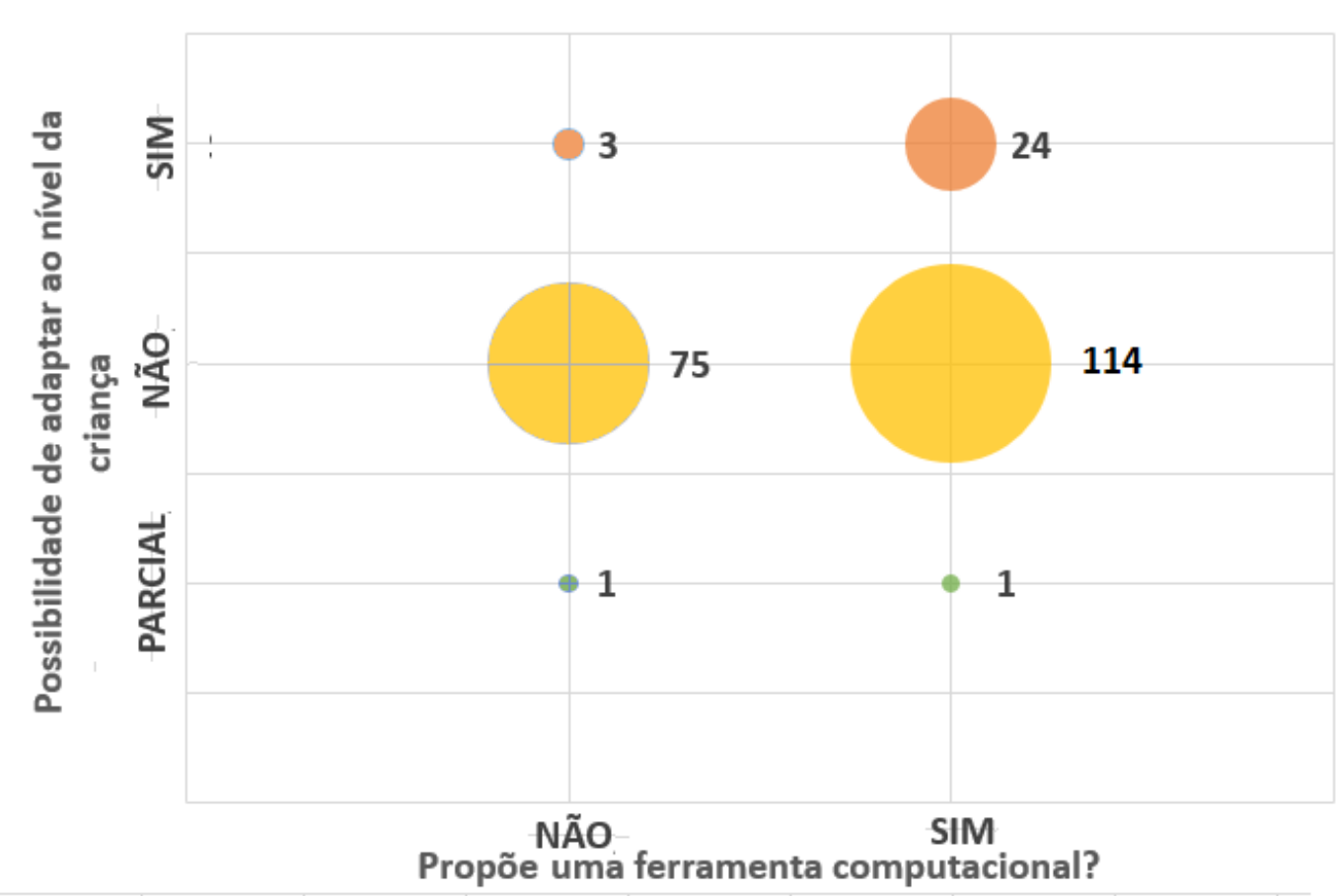

Figura 13: Número de artigos que apresentam ferramenta computacional de acordo com o nível de desenvolvimento da criança relacionando proposta com uma ferramenta computacional

Diante dos valores apresentados na Figura 13, especificamente, é possível avaliar que na adaptação com o nível da criança, de 27 trabalhos, 24 (SIM) são propostas que apresentam novas ferramentas computacionais. Ou seja, esses estudos que propõem ferramentas adaptáveis, em sua maior parte, vêm em ferramentas propostas. Já a Figura 14, a seguir, demonstra gráfico comparativo entre trabalhos que abordam a adaptação ao nível do indivíduo com TEA e trabalhos que realizam comparativo com o método tradicional.

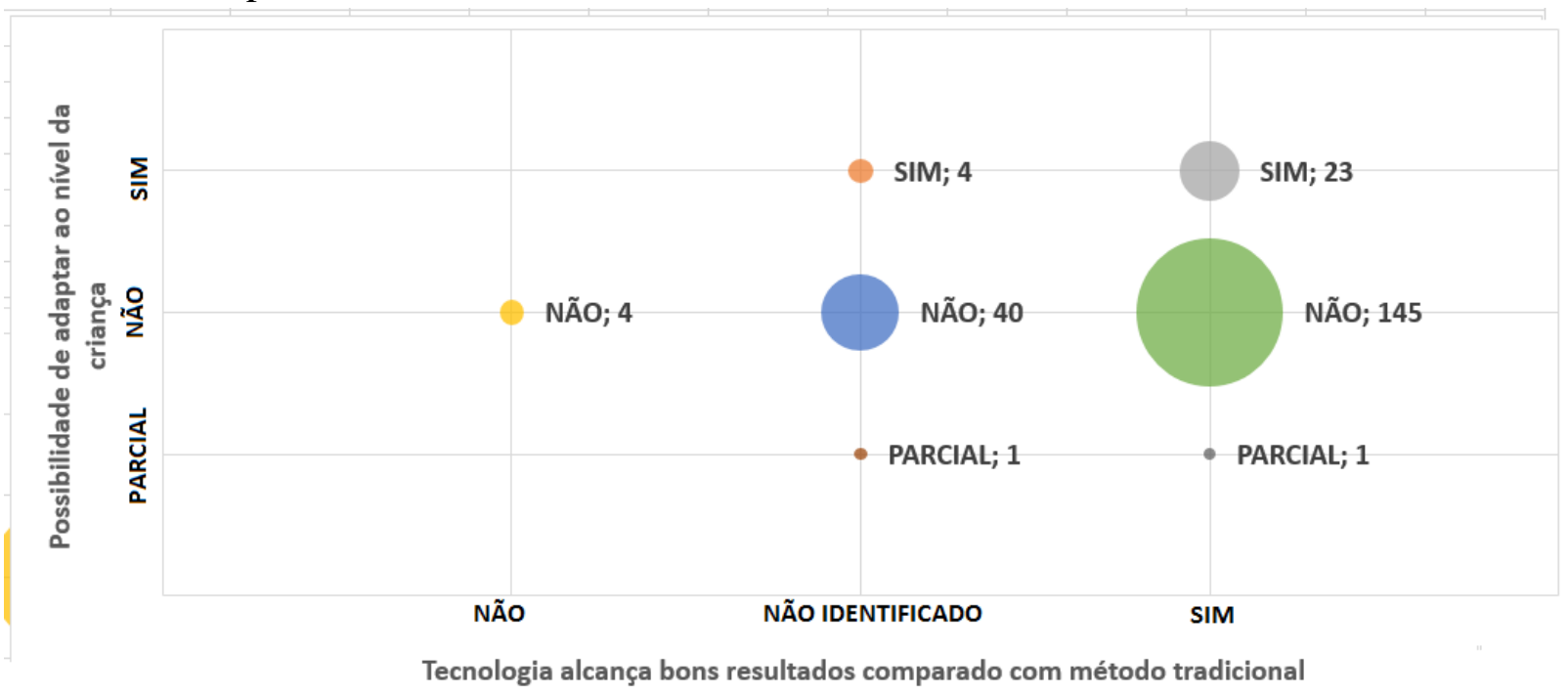

Figura 14: Número de artigos que apresentam ferramenta computacional de acordo com o nível de desenvolvimento da criança relacionando com o método tradicional

No cenário apresentado no gráfico da Figura 14, há um destaque evidenciado: dos 27 trabalhos realizados com adaptação ao nível de desenvolvimento da criança, 23 (SIM) obtiveram resultados equivalentes ou superiores ao método tradicional (sem uso de tecnologias).

Um ponto significativo em relação ao repertório vigente da criança com TEA é levar em consideração a idade da criança, o que é demonstrado na Figura 15, a seguir. 
Visualiza-se, por meio da Figura 15, que há uma expressiva quantidade de trabalhos que abordam tecnologias computacionais para a faixa etária infantil ( 0 a 11 anos): 171 estudos. Isso denota para o fato de que os trabalhos estão mais focados nas crianças autistas, visando ao ensino na idade certa.

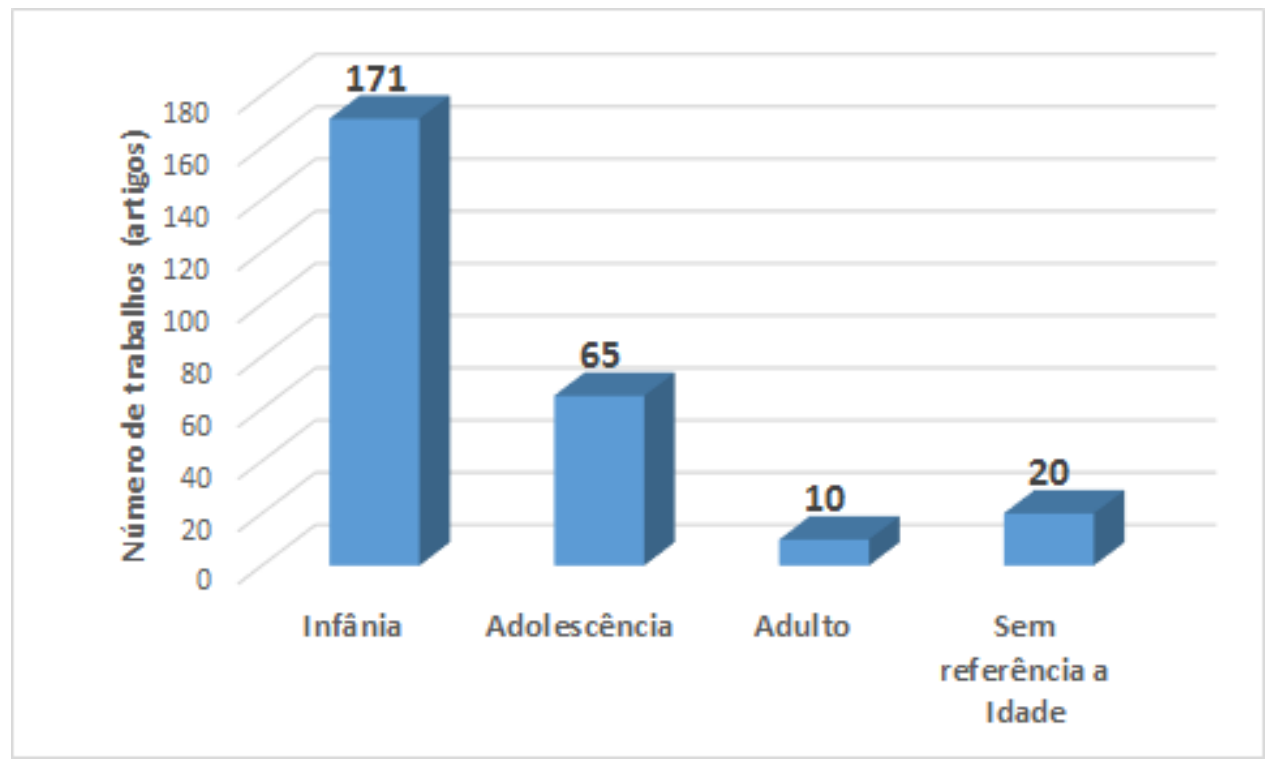

Figura 15: Número de artigos relacionados com a faixa etária da criança com TEA

QS6: Nas abordagens com o uso de tecnologias são comparadas com o método tradicional? A resposta para esse quesito, em boa parte dos trabalhos, é sim. Quando se examina o gráfico da Figura 16, a tecnologia utilizada alcança bons resultados (igual ou superior) - com 169 trabalhos - quando comparada com a forma tradicional de ensino, sem o uso de tecnologia computacional. Esse argumento é reforçado com a Figura 17: dos 139 artigos que propõem uma nova ferramenta computacional, existem 120 que afirmam alcançar bons resultados em comparação com os métodos tradicionais não computacionais.

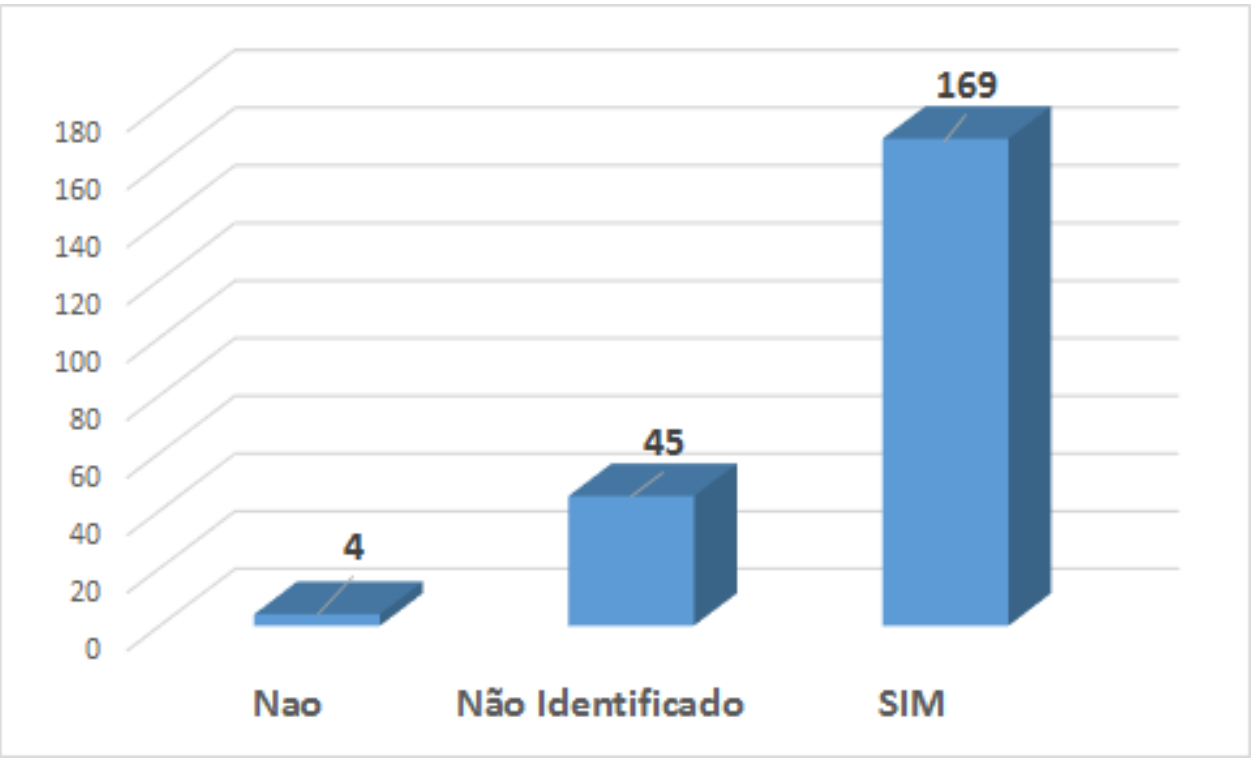

Figura 16: A tecnologia alcança bons resultados em comparação com o método tradicional?

Para o escopo desse quesito, deixam-se apenas as interpretações acima citadas. E este é o propósito do MSL: com os mapas ou gráficos montados, possibilitam-se a realização de inferências sobre o cenário da linha de pesquisa e a avaliação como relevante ou não. 


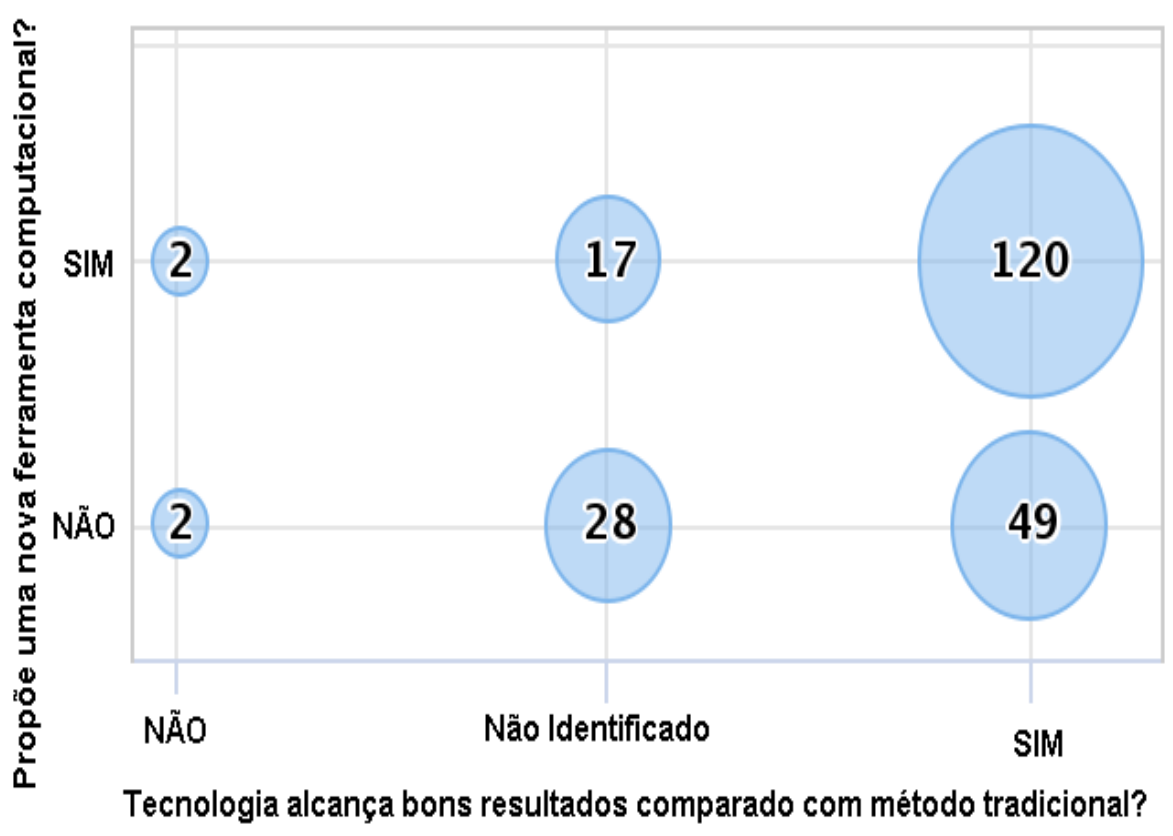

Figura 17: Número de artigos que apresentam nova ferramenta computacional relacionados com tecnologia alcança bons resultados em comparação com o método tradicional

\section{Discussão e conclusão}

QP: Como as ferramentas tecnológicas potencializam o desenvolvimento do ensino de crianças com TEA?

Este trabalho apresentou um MSL que teve por objetivo principal identificar a forma como as ferramentas tecnológicas potencializam o desenvolvimento do ensino de crianças com TEA. Tais ferramentas foram avaliadas levando-se em consideração alguns aspectos: o tipo e as abordagens de ensino utilizadas, as plataformas computacionais utilizadas, o modo como as ferramentas acessam os dados (local ou remotamente), se é utilizada estratégia com IA, se a ferramenta é adaptável ao repertório ou à necessidades da criança, comparado com faixa etária da criança e se há comparação com metodologia tradicional de ensino para criança com TEA.

Por meio desses aspectos, distribuídos em seis quesitos, foi possível fornecer uma visão geral dessa linha de pesquisa, identificar lacunas e oportunidades de futura investigação, além de facilitar a escolha de uma das ferramentas por parte de um profissional que precisa utilizar alguma delas.

Foram aceitos 218 trabalhos após a seleção, e algumas respostas às questões secundárias sustentam conclusões para responder à QP. De 2011 até 2016, houve um crescimento de 157\% de trabalhos relacionados ao tema deste MSL. Percebeu-se que a maioria dos trabalhos - 185 artigos - não faz uso de alguma abordagem de ensino (ABA, PECS, etc). Além disso, 60\% dos trabalhos utilizam plataforma mobile, sendo que, desses mobile, cerca de 90 trabalhos trazem uma proposta de uma nova ferramenta computacional. Ainda sobre a plataforma mobile, $65 \%$ deles trabalham com acesso a dados locais. Isso remete à revolução dos dispositivos móveis, dentro do contexto de tecnologias que potencializam o desenvolvimento do ensino de crianças com TEA. Por outro lado, verificou-se uma lacuna em relação aos trabalhos envolvendo IA, com apenas 6\% dos estudos. Em cerca de $87 \%$ das publicações aceitas neste trabalho, as ferramentas computacionais não possibilitam personalizar as atividades com base no repertório da criança com TEA. Já em relação à idade, verificou-se que, na maioria dos trabalhos, trata-se do assunto abordando a faixa 
etária de criança (171 artigos). Isso ressalta a importância de priorizar o ensino na idade certa. Em geral, há um cenário ainda com possibilidade para outras conclusões em relação às informações extraídas desses mapas.

Diante de todo esse contexto, foi possível levantar, numericamente, como as ferramentas possibilitam desenvolver o ensino de crianças autistas. Como já abordado, verifica-se que o número de trabalhos com ferramentas tecnológicas cresceu significativamente nos últimos cinco anos. Apenas um veículo consultado não apresentou representativa evolução, mas isso é justificável, por ser uma base de dados restrita a determinada área, a Psicologia.

Nesse cenário, crianças com TEA demonstram interesse em manusear e utilizar recursos computacionais (celular, tablet, jogos eletrônicos etc.). Por conta disso, essas ferramentas são inseridas cada vez mais nas terapias e nos processos de ensino e aprendizagem desses sujeitos (Passerino et al., 2006). Além disso, as atividades realizadas com uso de software favorecem a disponibilização de dicas visuais, em contraste com as atividades desenvolvidas com uso de papel e lápis. Quando tais atividades podem ser elaboradas em software ocorre a padronização da instrução, garantindo uma padronização na aplicação das atividades. Isso facilita que os pais possam aplicar as atividades em casa, assim como qualquer outro profissional (por exemplo, professor em escolas regulares), além de otimizar a análise dos dados. As dicas visuais são consideradas estratégias fundamentais para a aprendizagem do estudante com TEA. Portanto, os softwares viabilizam o uso de cores, luzes, toques na tela, animações, automatizações, entre outros Bernard-Opitz et al. 2004, Krantz e Mcclannahan 1998, Shabani et al. 2002).

Avaliando os resultados em todas as questões secundárias, as ferramentas tecnológicas expostas neste trabalho possibilitam o desenvolvimento do ensino de crianças com autismo. Ressalta-se, como forte fator de impacto, a evolução das tecnologias móveis. Outro elemento importante é que os trabalhos que propõem novas ferramentas, em sua maioria, abordam sobre a personalização das atividades de acordo com o nível de desenvolvimento da criança.

Por fim, vale ressaltar que há algumas lacunas nas pesquisas, com poucos trabalhos com IA, e há a necessidade de mais utilização de abordagens ou estratégias de ensino (como ABA e TEACCH). Dessa forma, este trabalho contribui para o avanço na área da informática, fortalecendo o incentivo a futuros trabalhos na linha de tecnologias computacionais para o desenvolvimento de crianças com autismo. Assim, é possível responder que as ferramentas computacionais potencializam o ensino de crianças com TEA.

\section{Referências Bibliográficas}

APA. American Psychiatric Association. Diagnostic and statistical manual of mental disorders. 5th ed. Arlington, VA: American Psychiatric Publishing, 2013.

Bernard-Opitz, V., Ross, K. and Nakahoda-Sapuan, S. Enhancing social problem solving in children with autism and normal children with computer assisted instruction. Journal of Autism and Developmental Disorder, v. 31, n. 4, p. 377-384, 2004. Disponível em: https://link.springer.com/article/10.1023/A:1010660502130

Braga, R. Oliveira, P. A., Souza, M., Andrade, G., Britto, R., Rabêlo, R. and Neto, P. S. Estudo Prático sobre Mapeamento Sistemático da Literatura utilizando a ferramenta TheEnd. Anais Escola Regional de Informática do Piauí, 1, 77-91, 2016.

CDC, Centers for Disease Control and Prevention. Estimated Prevalence of Autism and Other Developmental Disabilities Following Questionnaire Changes in the 2014 National Health Interview Survey. Disponível em: https://www.cdc.gov/ncbddd/autism/data.html. Acesso em 10 de maio de 2017. 
Dixon, W. J., Massey Jr, F. J. (1957). Introduction to statistical analysis.

Detroz, Juliana Patrícia; Hinz, Mauro; Hounsell, Marcelo da Silva. Uso de Pesquisa Bibliográfica em Informática na Educacão: um Mapeamento Sistemático. Revista Brasileira de Informática na Educação, [S.l.], v. 23, n. 01, p. 28, abr. 2015. ISSN 2317-6121. DOI: http://dx.doi.org/10.5753/rbie.2015.23.01.28.

Krantz, P. J. and Mcclannahan, L. E. Social interaction skills for children with autism: A scriptfading procedure for beginning readers. Journal of Applied Behavior Analysis, v. 31, p. 191202, 1998. DOI: 10.1901/jaba.1998.31-191

Kitchenham, B., Charters S. Guidelines for performing Systematic Literature Reviews in Software Engineering. Vol 2.3 EBSE Technical Report, EBSE-2007-01, Software Engineering Group, School of Computer Science and Mathematics, Keele University, Keele, UK, (2007).

Kitchenham, B. (2004). Procedures for performing systematic reviews. Keele, UK, Keele University, 33(2004):1-26.

Lakatos, E. M., Marconi M. A., Metodologia Científica, 5 ed., Atlas, São Paulo, 1991, páginas 43-44.

Mattos, L. K., Nuernberg, A H.. Reflexões sobre a inclusão escolar de uma criança com diagnóstico de autismo na educação infantil. Revista Educação Especial, n. 24 p.129-141. 2011. DOI: 10.5902/1984686X1989

Ozand, P. e. a. E autism: a review. Journal of Pediatric Neurology, n. 2, p. 55-67, 2016.

Passerino, L.M., Santarosa, L.M C. and Tarouco, L. M. R. Pessoas com Autismo em Ambientes Digitais de Aprendizagem: estudo dos processos de Interação Social e Mediação. Anais do SBIE 2006. DOI: 10.5753/cbie.sbie.2006.51-60

Petersen, K. F., Mujtaba S., M. Mattsson. Systematic mapping studies in software engineering. In: Proceedings of the 12th international conference on Evaluation and Assessment in Software Engineering, EASE’08, páginas 68-77, 2008. Disponível em: http://dl.acm.org/citation.cfm?id=2227115.2227123

Sahabani, D. B.; Katz, R. C.; Wilder, D. A.; Beauchamp, K. and Taylor, C. R.; FISCHER, K., J. Increasing social initiations in children with autism: Effects of a tactile prompt. Journal of Applied Behavior Analysis, v. 35, p. 79-83, 2002. DOI: 10.1901/jaba.2002.35-79

Wazlawick, R. S. Uma reflexão sobre a pesquisa em ciência da computação à luz da classificação das ciências e do método científico. Revista de Sistemas de Informação da FSMA, 2010, 6:310 . 